\title{
Let's Play ... eGovernment! A Simulation Game for Competence Development among Public Administration Students
}

\author{
Nadine Ogonek \\ University of Münster \\ nadine.ogonek@ercis.uni- \\ muenster.de
}

\author{
Bettina Distel \\ University of Münster \\ bettina.distel@ercis.uni- \\ muenster.de
}

\author{
Jörg Becker \\ University of Münster \\ joerg.becker@ercis.uni- \\ muenster.de
}

\begin{abstract}
The rollout of eGovernment is in full swing worldwide, because of governments' realization of its possible efficiency and effectiveness gains. The introduction of service accounts, as exemplary initiation of the European eID strategy in Germany, is one of the eGovernment projects that keeps the German public sector busy. Owing to the federal structure of Germany, the nationwide implementation poses an extraordinary challenge. With this, it forms a good example for the complexity of eGovernment projects in federal states. (Future) public servants need to have a full understanding of the interdisciplinary environment, they will need to operate in.

Simulation games, offering the possibility of immerging into a subject matter in a neutral, risk-free environment, are increasingly used in educational programs in times of digitalization and therefore could represent a powerful tool to teach the needed eGovernment competences. At the same time, they help to early sensitize eGovernment students to the numerous exigencies in their working life. We developed a simulation game, targeting the introduction of service accounts in Germany, and tested it with an international student group $(n=16)$ to measure its potential for competence development in higher education programs in eGovernment.
\end{abstract}

\section{Introduction}

In an attempt to increase the public service delivery, public administrations worldwide are eager to adopt electronic government (eGovernment) because of its huge ascribed potential in terms of cost savings and efficiency gains [3,22,29].

That is the reason why policy makers everywhere put huge efforts in pushing it as priority on the political agendas and defining strategies and standards for simplifying its introduction and implementation within and beyond national borders. An example for such a strategy is the European Commission's Digital Single Market Strategy, with the digital transformation of governments being one of its success factors [11]. Within this strategy, the eGovernment action plan 2016-2020 is a policy that shall guarantee a smooth cooperation on the European level, which can be seen as joint efforts between all member states to increase the level of eGovernment. Herein, core principles are defined that should be taken into consideration when designing new services. One of those principles to reduce administrative burdens across borders being the once only principle, which has that data - in compliance with the respective laws and framework conditions - need to be collected only once and are stored and shared for future purposes. Another principle is digital by default, stating that all public bodies' preferred type of communication should be the digital one, while also keeping other channels in place. Both of these principles are enabled and made secure across Europe by means of technological key enablers such as the electronic identification (eID), enforced by the eIDAS regulation $[14,15]$. Comparing the scores on the eID availability, countries like Denmark (score 100), Malta (score 94) and Estonia (score 76) are outperforming Germany (score 68) [14].

The implementation of the eID strategy with a focus on the service accounts is one of the core projects of the German IT planning council - the central federal body for advancing cooperation on information technology - since the dissemination and use of electronic identities by citizens and legal persons plays a key role for the national eGovernment strategy [17].

A service account enables citizens and businesses to digitally manage and exchange their affairs with the respective public institution. Despite its strategic purpose, Germany is still facing issues in advancing with the implementation of service accounts. According to [1], only $25 \%$ of the German citizens currently uses some kind of digital channel for administrative purposes, due to the limited availability 
of data and documents in a digital format, an equally limited adoption of eID means and the lacking interoperability of existing service accounts.

eGovernment, as it is treated by overarching political executive institutions such as the EU, can be broadly referred to as "[...] the use of information and communication technologies in public administrations combined with organizational changes and new skills." [10] Hence, we are focusing on the provision of eservices to different stakeholders and not on governance aspects. This is a mandatory prerequisite in order to make use of the whole array of benefits, it is able to provide, even beyond national borders.

Yet, it seems that especially the adequate competence provision is a considerable challenge for public sector institutions [12], while it constitutes a decisive factor, since "[s]uccessful digital transformation does not come from implementing new technologies but from transforming an organisation to take advantage of the possibilities that new technologies provide. [...] this also requires that all people in an organisation - leadership, IT professionals, employees in other divisions - obtain the skills to embrace technology." [13:76f] For this reason, it is indispensable to introduce future public servants as early as possible and as close to reality as possible to the peculiarities of their working environment.

Given that the introduction of service accounts is an enduring and very complex project that involves many different stakeholders on all different political levels in Germany, to understand the mechanisms, dependencies and challenges of all players involved can be very difficult for an outsider. Especially when laying the grounds for a basic comprehension of eGovernment procedures, it is hard to understand these complex structures that oftentimes are disconnected from the students' experience. "Even when the relevance of international affairs to everyday life is recognized intellectually, it is difficult to give the student a sense of how it feels to be a decision-maker at the national and international level." [36:269]

This is the reason why we developed a simulation game to mimic the introduction of service accounts and let the players get an impression of the complexity inherent to this process in a federal state like Germany. This game should serve as tool for competence delivery in the field of eGovernment. In terms of its current design, it primarily aims at shaping an understanding of the German federal structure, its laws and regulations as well as reasonable decision-making, communication and negotiation.

A simulation game, sometimes also called serious game to avoid the impression of fun being the primary source for its use [44], puts human participants into a fictitious setting in that they have to act according to a role description and a set of rules, emulating a certain aspect of real life. For this game, a group of 16 international Master students with a specialization in the Public Sector was the test group in which each student incorporated a different role. With regard to peculiarities of the German administrative system, the simulation game was accompanied by a mandatory lecture to provide the students with substantial information on the initial scenario. During and after its completion, we evaluated the use of the game for the development of students' eGovernment competences.

This paper is structured as follows: First, we draw on advantages as well as possible drawbacks of using simulation games for higher education and elaborate on the competences needed by public servants in a digital public sector. In the next session, we describe the structure of the simulation game, i.e. the roles, responsibilities and general course of action. In section four, we present different evaluating elements, discuss the potential implications of simulation games and draw conclusions.

\section{Related work}

Simulation games and game-based learning have become more and more popular in higher education in recent years $[2,32,35]$. This can be mainly ascribed to two reasons. First, they offer the possibility to mimic real life scenarios in a risk-free environment and therefore are ideally suited for learning and practice settings and second, they have an entertainment factor that increases the students' motivation by engaging them in an interesting and exciting case $[18,41,44]$. It can help to increase the students' understanding of new phenomena and situations [18]. According to [42], it is indispensable for learning to happen to become active and not only to listen to what is taught, since this does not necessarily lead to the intended results.

However, the development of a simulation game also comes with a price, i.e. the time and resources needed to sufficiently prepare such a complex game, involving a multitude of different players. [32], for example, conducted a survey within a UK higher education institution and identified the limited time available for teaching development as well as limited technical and administrative support for the use of new methods as main barriers to its use. This is also backed by [36,42], who argue that the development and actual implementation of a simulation game is costly in terms of time and resource allocation. This might also be a reason why the scientific literature on the use of simulation games for eGovernment is scarce. [31], for example, developed a simulation game for public service delivery, fostering collaborative development in eGovernment. [4] created a fully virtual simulation 
game to support policy makers and involve citizens in the policy making process.

At the same time, simulation games are particularly suitable to "[...] address the changing competences needed in the information age: self-regulation, information skills, networked co-operation, problem solving strategies and critical thinking." [44:420] This is backed by [34] who sees a huge potential in gaming with regards to the use technological projects and for learning and training, as well as for policymakers.

As elaborated before, it is especially the targeted competence provision that falls short of expectations in the design of eGovernment curricula and does not meet the actual demands $[24,39,40]$. Furthermore, "[...] in many cases, the inclusion of innovation in HRM policies and practices does not often extend beyond a passing reference and does not expand in detail the specific skills and capabilities needed." [38:4].

Scientific literature on competence needs in eGovernment, however, is limited. Coming from a mere call for more IT skills of the public workforce $[28,30,43]$, the limited scientific debate has developed since then into the direction of acknowledging the need for a broader skillset that better fits the diverse working environment of public servants today [25,26,27].

A promising approach to structure eGovernment education by gathering and deriving competence categories from scientific literature has been made by [24]. Table 1 summarizes their identified competence categories: technical, socio-technical, organisational, managerial and political-administrative competences, exemplifying different characteristics.

Table 1. Competence categories by [24]

\begin{tabular}{|l|l|}
\hline Category & $\begin{array}{l}\text { Exemplarily assigned knowledge, } \\
\text { skills, competences }\end{array}$ \\
\hline technical & $\begin{array}{l}\text { information technology skills; IS design } \\
\text { competence, information systems }\end{array}$ \\
\hline $\begin{array}{l}\text { socio- } \\
\text { technical }\end{array}$ & $\begin{array}{l}\text { e-government impact; technology and e- } \\
\text { government adoption; politics of e- } \\
\text { government }\end{array}$ \\
\hline organizational & $\begin{array}{l}\text { e-government structures; organizational } \\
\text { design; process management }\end{array}$ \\
\hline managerial & $\begin{array}{l}\text { Business skills; project management, } \\
\text { financial management, performance } \\
\text { management; change management }\end{array}$ \\
\hline $\begin{array}{l}\text { political- } \\
\text { administrative }\end{array}$ & $\begin{array}{l}\text { e-policy competences; legal framework, } \\
\text { administrative workflows; public policy }\end{array}$ \\
\hline
\end{tabular}

Technical skills are all those skills that concern the mere computing and programming skills that are the prerequisite for the existence of eGovernment. Sociotechnical competences refer to skills at the interface between human beings and technology. They are needed to shape an understanding and equal consideration of both of them, in order to make use of the full benefits. Organizational competences consist of knowledge of the organizational environment in which eGovernment operates, whereas managerial competences can be considered as rather traditional business skills, needed to lead and control a company. Finally, political-administrative competences include the knowledge about and understanding of the political and legal landscape eGovernment is embedded in.

Besides those primarily task- and job-specific "hard" skills public servants need to have, a study among European public administration professionals revealed that even though all of those competence categories are relevant to a certain degree, there is also a strong need for a diverse set of soft skills. Those include skills like communication, negotiation, team and persuasion as well as decision making skills amongst others [40].

\section{The simulation game}

\subsection{Development of the game}

The overall aim of this simulation game is to equip students with competences that cannot be taught through rather classic formats of instruction, such as cooperation, strategy development, and decision making. The design of the game also allows the students to gain a deeper understanding of decisionmaking processes in (e-)Government projects in a federal system. Owing to this objective, the simulation game does not focus on technological aspects but more on political questions as well as on managerial and organizational impacts of the digitalization.

The development of the game is mainly based on the authors' knowledge, experience and results gained in a variety of eGovernment-related research projects. The game primarily targets the competence provision of public administration students. Competences that currently are insufficiently addressed with common study programs are covered with the simulation game $[24,40]$ as is depicted in table 2 . Research on public administration employees and the implementation of IT projects revealed various issues such as resistance to IT-related projects [21], and legal issues [8,21]. These and other important issues are addressed with the simulation game as well.

\subsection{Design \& starting scenario}

The simulation game is situated in Germany and as an overall scenario, the introduction of service accounts was deemed appropriate for two reasons. First, it offers interaction possibilities for a variety of stakeholders operating in the German eGovernment landscape. Second, this scenario can be considered a 
realistic setting as it is actually part of the German digitalization agenda [19]. Due to Germany's federal structure, stakeholders at all federal levels as well as non-governmental organizations have to be included for a successful and extensive implementation and nationwide coverage of service accounts. Thus, various roles with different, sometimes opposing opinions are integrated in the simulation game. As [31:4] point out, a simulation game is an "[...] abstraction of reality and should capture the main complexities that need to be addressed when developing e-government." Anchored in the conception and initiation phase of the service account project, we cover political questions as well as managerial and organizational impacts the administration of an IT project faces, such as organizational resistance, changing political balances of power, and economic pressures. We intentionally decided to not consider purely technical issues in this simulation game, as they are just one of the decisive factors. "[P] rojects need to develop and use 'hybrid' professionals, who understand both perspectives. We might even call them 'tribrids' because they combine three aspects: understanding the technology and the business of government and the role of information in government."[23:11] Furthermore, the technology perspective will be dealt with in detail during the students' semester focus on information systems. The game is designed to take place over a period of three months and is accompanied by an introductory lecture to eGovernment and the administrative system in Germany but may as well stand alone. In this case, due to the heterogeneity (EU and non-EU students, from federal and centralist countries) and internationality of the student group, however, we deemed a general introduction to the German structure important. The game consists of a set of (mandatory) sessions during which all players meet and exchange important information. These sessions are accompanied by informal and non-obligatory sessions, during which the players can meet and discuss. The core of the game, though, are five events. Each event has a fundamentally changing influence on the initial scenario. Certain tasks come along with those events where the players have to react in accordance with their roles' overall aims. They also have to prepare certain actions that address issues raised through the events.

The simulation game is accompanied by three reflections the students have to write at the beginning of the game (expectations), during the game (midterm) and after the completion of the game (final). Those reflections are not only a helpful instrument to monitor the game but also to evaluate the educational impact. The evaluations facilitate the improvement process during the game and help to change the course where needed, as depicted in Figure 1.

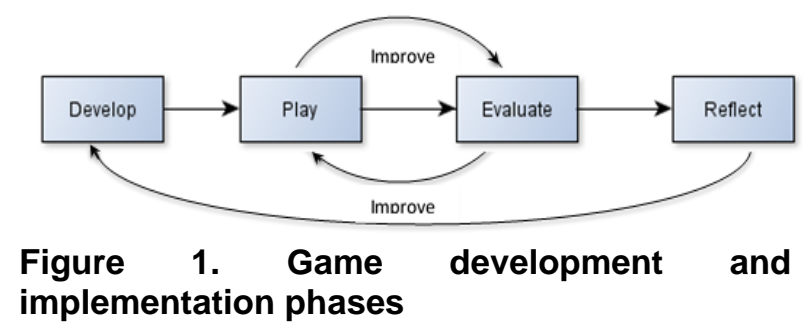

Although the starting scenario as depicted above as well as the included roles are based on the situation in Germany, the simulation game is designed flexibly and in a way that enables the adaptation to other nations or contexts. The number of players can be reduced or increased, roles can be assigned to more than one player and events can be altered. It is supported by a Moodle platform, where all necessary information is published and shared between lecturers and players. Moreover, the students can use the internal messaging functions to interact with each other in private sessions.

\subsection{The roles}

In total, we included 16 roles for this game, situated at different federal levels. The Federal Government of Germany was included as the party enacting laws and specifying the general direction of digitalization efforts for the whole country. Although the Federal Government is the highest administrative unit, laws such as the eGovernment law are only effective for the federal agencies [16]. Each state has to pass own laws to direct its course of action and the course for local government agencies. Hence, two states, North RhineWestphalia $(N R W)$ and Saxony, were included as roles. The former was chosen as it is the most populous state in Germany and Saxony, because of its role as a frontrunner in terms of digitalization. Whereas Saxony invests resources in digital projects, NRW has to face many challenges that require most of the available public budget, such as poverty and unemployment. On the local government level, two municipalities are included, Bautzen and Dresden, two cities that are both located in Saxony. While Dresden is a big rich city with an important history that attracts millions of international visitors each year, a renowned university and flourishing economy, mainly tourism, Bautzen is a small city in the orbit of Dresden and is considerably less wealthy. Both cities, however, are directly affected by decisions made on the state level.

As political players, we included two parties, a liberal and a right-wing populist party. We made this decision, owing to a European-wide observable, 
political trend that populist parties gain more and more popularity and, thus, political importance [20]. While the liberal party in our setting supports digitalization efforts, the right-wing party opposes digitalization in general. This notion of proponents and opponents of digitalization prevails in all roles with a varying intensity and is a realistic imprint of the current political situation in Germany.

As potential users of service accounts, we included two fictive businesses in the scenario. One business is a large IT company that is eager to realize any contact with administrations as efficient as possible and is, therefore, a great supporter of service accounts. The second business, though being internationally successful, is a long-established local mustard manufacturing company and as such, feels more obligated to the region and its inhabitants than to the greater goal of digitalization.

The IT company is represented by a lobbyist association for telecommunication businesses in Germany that exerts influence on the government in IT-related decisions. As second lobbyist, we included an association representing the interests of German cities and municipalities. As such, they are not opponents of digitalization per se but see the reasons for many of their members struggling with the costly implementation and therefore repeatedly point to the financial and economic constraints especially smaller cities in Germany face.

Commonly, the municipalities, cities and states in Germany have municipal IT providers, who advise administrations, and implement and operate municipal IT infrastructure. The game includes two municipal IT providers, who are entrusted with the procurement and operation of e-services. Naturally, both roles are in favor of sophisticated and sustainable digitalization efforts, but they are as well aware of the financial and economic burdens for the municipalities that come along with the digitalization.

Closely related to the IT providers are the software producers, two companies specialized in the development of office and enterprise solutions. They are competitors in the fight for contracts with public administrations. One of the software producers is rather small with a limited client base, trying to offer customized solutions for their customers. The other software producer is close to becoming the market leader and thus, is a proponent of offering standardized solutions that are easy to implement and maintain, not putting too much effort in serving the single customer's wishes and needs.

Finally, the game includes a journalist. This role has a different mindset than all the other roles, observing the events, stakeholders and their actions. The journalist is not determined to take a position but is free to shape her role in any way she wishes and to influence the course of the game with either neutral, positive or negative coverage of the events.

The creation of the roles was greatly oriented on existing stakeholders in eGovernment projects in Germany, although not every interest group could be included. Citizens, for example, who are only seldom integrated in the initiation phase of eGovernment projects were not considered. Although all stakeholders are oriented towards existing entities, the roles are exaggerated at times to highlight the prevailing dependencies, constraints, and scopes of action.

Every student is assigned to one of the above sketched roles and receives basic information on the role and her personal goals. While the students are asked to play their roles as realistic as possible, they are free to make decisions not anticipated by the instructors. Moreover, they are free to interact with each other, form alliances, and to share or withhold important information. All roles as well as relationships are depicted in Figure 2. The green connections show roles with a similar mindset or similar strategic goals, red connections indicate (possibly) conflicting interests.

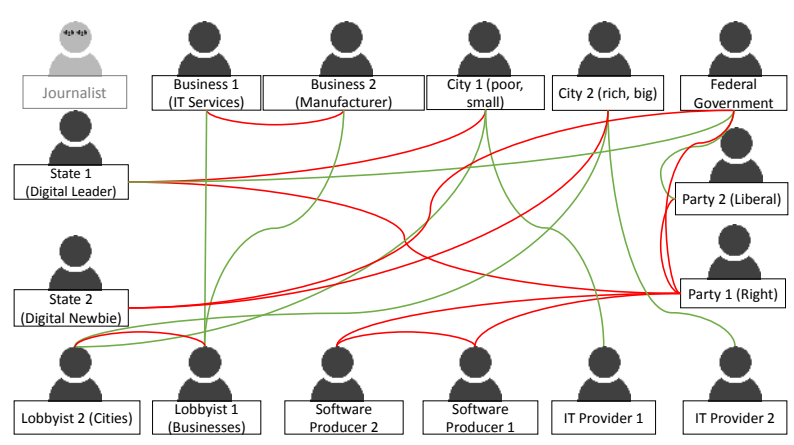

Figure 2. Game roles and relationships

\subsection{Events \& associated tasks}

Five events shape the simulation game that may act either as episodes, i.e. they stand alone and have no consequences for further events, or as milestones in the course of the game, i.e. each event changes the scenario and influences the subsequent events.

The first and introductory event in this simulation game is a conference on the topic of "digital transformation of public administrations". The neutral journalist has to give a key note on the status quo of service accounts in Germany, all other players have to give a short overview of who they are and what their positioning is with regard to the comprehensive implementation of service accounts in Germany. One of the lecturers acts as moderator. This event mainly serves to give all players a condensed overview of the 
actors and to establish first insights on who potential collaborators in this game could be.

The second event is a data leakage detected at the Federal Ministry of the Interior by which sensitive personal data of citizens and businesses were accessible for non-authorized third parties for several hours. This event is an incident that puts emphasis on security and technical aspects that have to be considered when implementing service accounts.

Opponents of the project are encouraged in their view by this event, while the supporters' efforts are set back. This event mainly touches upon a, on the one hand, technical and, on the other hand, affective dimension of eGovernment projects and is constructed to reinforce existing opinions and positions. IT security and privacy matters are a major consideration and constitute a prominent concern in the implementation of eGovernment (business, citizens and administrations) that have to be adequately addressed and provided for by the implementing institution [6,9].

The third event is the bankruptcy of Bautzen. The city is so highly in debt that necessary investments cannot be arranged and cost-intensive projects such as the service account introduction are cancelled. In fact, German cities cannot declare bankruptcy strictly speaking. They are obliged to have a balanced budget and in case municipalities cannot balance their budget, they come under control of higher administrations and have to develop a concept to consolidate their budget (see for example: Municipal Code for North RhineWestphalia [37]). As a lot of cities and municipalities in Germany are struggling financially and some of them are actually in the situation to be under a higher administrations' financial surveillance, this event represents a real threat to the successful implementation of eGovernment projects. This event is accompanied by a TV talk show during which some of the players have to advocate their positions and engage in discussions with the audience. The players not participating in the show act as audience and are asked to pose (critical) questions and engage in discussions.

The fourth event is a political event. The right-wing populist party wins the latest state elections in Saxony and declares a governmental program in which digitalization is to be abandoned. In recent years, European and other western countries have faced a considerable swing to the right that entails "[...] policies that seek to turn back the clock and reestablish eras of more homogenous demography, rigid hierarchy, and protectionist economics." [20:2] Although these parties are not necessarily digitalization adversaries, they are commonly elected by citizens who are afraid of change in general. Digitalization is considered to fundamentally change the society. In this case, the populist seems to be the most probable one to oppose digitalization efforts. Again, we used exaggeration as a stylistic element to stress important aspects. This event requires the students to react to changes in the political agenda of a nation, state or municipality, to position their roles in a changed power structure and to newly negotiate their positions and alliances.

The fifth and last event forms the official closure of the simulation game. Here, all players are invited to participate in a Digital Summit where they present their vision for the future of the service accounts in Germany, taking into account the past events and recent developments. This requires the students to reflect upon what has happened so far and try to think strategically, but realistically about the future. The players should design a poster that sketches their ideas and present them to a bigger audience.

\section{Educational approach and competences addressed}

Table 2. Intended competence coverage by the simulation game

\begin{tabular}{|c|c|c|c|c|c|}
\hline Competences & 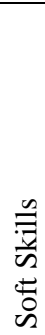 & 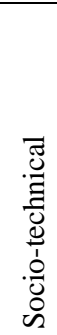 & 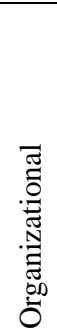 & 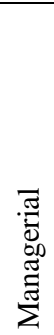 & 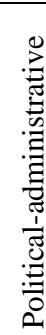 \\
\hline Scenario in general & 0 & 0 & 0 & 0 & 0 \\
\hline Interaction with other players & 0 & & 0 & 0 & 0 \\
\hline Presentations & 0 & & & & \\
\hline $\begin{array}{l}\text { Information gathering for } \\
\text { events }\end{array}$ & 0 & $\theta$ & 0 & & 0 \\
\hline Event 1 (conference) & 0 & $\theta$ & 0 & 0 & 0 \\
\hline Event 2 (data leakage) & 0 & 0 & & 0 & 0 \\
\hline Event 3 (bankruptcy) & 0 & & & 0 & 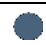 \\
\hline Event 4 (elections) & 0 & & & & 0 \\
\hline Event 5 (digital summit) & 0 & 0 & & $\theta$ & 0 \\
\hline
\end{tabular}

By means of the different elements and the scenario in which the students are put, we intend to create a learning environment that is as close to the eGovernment reality in Germany as possible in order to shape the competences, public servants should ideally master. We oriented ourselves on the competence categories by [24], leaving out the technical competence category, as was mentioned before and instead adding soft skills to the mix of needed competences, as identified by $[5,33]$. Table 2 
comprises the different elements of the game and the respective competences addressed by those elements. Fully colored circles indicate a total coverage of the competence, semi-colored circles indicate that the competence is partly covered, though not representing the main focus of the event.

As can be seen, the simulation game covers all of the indicated competences, while the focus clearly lies on the coverage of soft skills and political-administrative skills. The latter is because we designed the game in a way that primarily should facilitate the understanding of the complex decision making structures that are inherent to a federal system as well as the political environment that encourages/hinders the implementation of nation-wide eGovernment. Soft skills are increasingly in demand for people working in public institutions, especially when being hired for the advancement and implementation of eGovernment, since they act as mediators between the different kinds of employees, communicating and negotiating between the technical and organizational interests of the stakeholders involved. In order to do this, they also need socio-technical competences, i.e. understanding and respecting both sides of an information system, the users as well as the system itself [7].

\section{Reflections \& evaluation}

\subsection{Aim of reflections \& evaluation}

In order to judge on the success of the simulation game in terms of its competence delivery and overall satisfaction of the students, it is complemented by three reflections and a final survey via the Moodle platform, used throughout the game. Simulation games are successful if they succeed in completely involving the players and transferring them to the simulated world $[32,41]$.

The game starts with an introductory session in which the setting is explained and roles are assigned. After this session, the students shortly articulate their expectations regarding the game and its educational impact in a short essay. After the completion of the first event, the students again evaluate on how the game met those expectations and on what they (dis)liked so far. At the end of the simulation game, the students hand in a final reflection (after all five events are completed). Only then, they are able to fully reflect the game.

The reflections serve a twofold goal. First, the students have to reflect on the game and its educational impact. Thereby, they can connect teaching contents from the lecture with the simulation game, lessons learned can thus be strengthened. Second, it enables the instructors to monitor the games' process and to intervene, if necessary (see Figure 1).

In addition to these three reflections, the simulation game is evaluated through a survey. Since it is designed as a tool to enhance the students' competences, it is important to monitor in how far each of the competence categories (see Table 1) is actually addressed from a student's perspective.

\subsection{Results of the reflections}

By the time of the manuscript's submission, two out of three reflections were written by the students and could be evaluated. The issues raised in these reflections are discussed according to their topic. In general the reflections were very constructive but show quite heterogeneous expectations and experiences. In total, we identified four areas for improvement.

Background Information. Some of the reflections revealed a lack of information from the students' perspective with regard to the game and its outcome. They wished for more information on the rules that guide the players' (inter)actions as well as mechanisms to sanction improper or unrealistic behavior. One student wrote that "I think some more guidance and hand-holding would be beneficial, especially at the beginning stages of the game so that everyone is comfortable with the concept." Therefore, we decided to give more input for the following events, detailing possible actions for the role players.

As the students had diverse backgrounds, for some it was hard to find enough and relevant information on their roles and their scope of action as a lot of information is only available in German. Moreover, there were students among the group with no background in public administration and with no experience with federal systems. Relating to this, one student raised the issue of the game's dependency on profound research and information gathering. We addressed this issue by compiling important information and translating it to English where necessary. Thereby, we were also able to better guide the direction of the game by providing relevant information to the students.

Transfer of Knowledge. One major component of the game is the transfer of knowledge through an innovative teaching method. While most of the students appreciate this 'experiment' as an intriguing and attractive approach, they also raised concerns about the actual output. On the one hand, students expected to learn about difficulties related to the implementation of e-government solutions in general and the German case in particular. They also expected to learn about legal, political and socio-economic aspects of the eGovernment landscape in Germany and 
Europe. On the other hand, some students criticized that especially the international perspective is missing in the game. Therefore, they raised doubts about the generalizability of the game for other contexts within Europe. As a consequence for future iterations, we decided to provide more information on the general scenario, the game's scope and learning outcomes.

Soft Skills and Social Skills. Nearly all students expected to enhance their soft and social skills and as the reflections reveal, those expectations were met. One student stated "To start with what I like about the game, it is observable that most of us are improving presentation skills since we have to present in front of the audience." Among the skills students were able to improve are communication and negotiation skills, leadership skills, presentation skills as well as skills in decision making. In how far other skills or competences were trained through the game is evaluated through a short survey (see section 5.5).

Format. The students also gave feedback on more formal aspects of the game, which is also the major area for improvement. So far, all events are accompanied by some form of written evaluation from the students' part, i.e. press releases and presentations they have to prepare. While the game also includes a talk show, a conference and discussion rounds, the game could profit from periodic and more informal meetings during which the players can discuss their plans and actions and form alliances. For future iterations of the game, these discussion rounds will be incorporated, while the written assignments will be reduced.

\subsection{Results of the survey evaluation}

We conducted a short survey to evaluate in how far the competences (see section 4 ) were actually addressed by the game. While the students' reflection were not explicitly geared towards this aspect, the survey solely focusses on the development of competences.

For each group of competences (see Table 1), four to six questions were developed, measuring the extent to which the competence group was trained through the game. Table 3 gives an overview of exemplary questions for each group. The statements were rated on 5-point scale, ranging from "1 - completely disagree" to "5 - completely agree". We received 14 responses. Descriptive statistics are shown in Table 4.

Table 3. Exemplary questions for the evaluation of trained competences

\begin{tabular}{|l|l|}
\hline Category & $\begin{array}{l}\text { Exemplarily assigned knowledge, } \\
\text { skills, competences }\end{array}$ \\
\hline technical & - not addressed with the game - \\
\hline $\begin{array}{l}\text { socio- } \\
\text { technical }\end{array}$ & $\begin{array}{l}\text { The simulation game helped me to } \\
\text { understand the change processes }\end{array}$ \\
\hline
\end{tabular}

\begin{tabular}{|l|l|}
\hline (soctec) & induced by increased technology use. \\
\hline $\begin{array}{l}\text { organizational } \\
\text { (orga) }\end{array}$ & $\begin{array}{l}\text { The simulation game helped me to } \\
\text { understand the interdependencies } \\
\text { between the different organizational } \\
\text { stakeholders involved. }\end{array}$ \\
\hline $\begin{array}{l}\text { managerial } \\
\text { (man) }\end{array}$ & $\begin{array}{l}\text { The simulation game helped me to } \\
\text { understand IT management processes. }\end{array}$ \\
\hline $\begin{array}{l}\text { political- } \\
\text { administrative } \\
\text { (polad) }\end{array}$ & $\begin{array}{l}\text { The simulation game helped me to } \\
\text { understand the influence of political will } \\
\text { on e-government projects. }\end{array}$ \\
\hline $\begin{array}{l}\text { Soft Skills } \\
\text { (soft) }\end{array}$ & $\begin{array}{l}\text { The simulation game helped me to } \\
\text { improve critical thinking skills. }\end{array}$ \\
\hline
\end{tabular}

Students agreed with having ameliorated their competences in three categories (socio-technical, organizational and political-administrative competences). Surprisingly, the students rated soft skills less positively than the reflections suggested. This may be due to the fact that the survey was run during the game. Thus, the students were not able to fully evaluate the game as some of them pointed out in open comments at the end of the questionnaire. On the other hand, this evaluation demonstrates that the transfer of managerial competences and soft skills should be improved during the next run of the game. In general, the reflections and the short survey show that the first run of the game was a success, but they also reveal areas for improvement. At this point it should be re-emphasized that the game has to be adapted for each group, their prior knowledge and carefully monitored during the conduct.

Table 4. Evaluation - descriptive statistics

\begin{tabular}{|l|l|l|l|l|l|}
\hline & soctec & orga & man & polad & soft \\
\hline Mean & 3,15 & 3,29 & 2,46 & 3,23 & 2,85 \\
\hline Median & 3 & 3,33 & 2 & 3,2 & 2,6 \\
\hline Min & 1,25 & 1,16 & 1,5 & 1,2 & 1 \\
\hline Max & 5 & 4,5 & 4 & 5 & 4,4 \\
\hline SD & 1,27 & 0,91 & 1,07 & 1,23 & 1,15 \\
\hline
\end{tabular}

\section{Discussion}

We developed this simulation game with a twofold goal. First, the simulation game served to create an understanding for the complexity of decision-making processes in eGovernment in a federal system such as Germany for international students who are not familiar with these structures. We chose the introduction of service accounts, which on the one hand it is highly topical with regard to the status of eGovernment in Germany and on the other hand, involves a variety of different stakeholders on all political layers and thus, represents a reflection of Germany's reality. Second, it served as a tool for competence development, where the competence 
provision was incorporated by the different existing roles and the tasks - evoked by the five events that change the course of action - the players had to fulfill and act according to their role's orientation.

A simulation game can help to gain first-hand insights into situations that are not known to the individual and thus, offer an environment that is ideally suited to practice what is needed later on in corporate contexts [41]. Incorporating a simulation game in eGovernment education thus could support a competence provision that is close to the public servants' needs and offers an integrated perspective on the interdisciplinary nature of competences, instead of offering isolated approaches that do not suffice to close those gaps [24,39]. It has to be emphasized, though, that, as the evaluation shows, employing a simulation game in the education is not a self-fulfilling prophecy and does not guarantee a more targeted provision of the necessary competences. It very much depends on different variables. First, the construction of a scenario needs to be as close and as relevant to the learner's reality as possible. Then, the learners need to take the game serious and obey to the rules that are in place to make it a success. Despite those constraints, the use of a simulation game can help to illustrate realistic situations that are normally not known or not that easy accessible to a learner without any practical experience. Thus, this game could be used as a valuable template that can and needs to be adapted according to the competence provision aimed at and to the target group. While groups with a similar educational background that have had previous experience in this domain do not need a lot of extra information, we made the experience that heterogeneous groups that are further away from the topic in question, need more guidance and introduction.

\section{Conclusion \& Outlook}

In this paper, we introduced a simulation game as a means to transfer knowledge and train competences of public administration students with an innovative and practice-oriented teaching method. The evaluation of the test run shows that the students appreciate this form of learning and were able to actually improve their competences. However, the evaluation also revealed areas for improvement such as the restructuring of written assignments and interactive parts within the game. Our findings are based on a small sample and may thus not be generalizable. The game has to be repeated several times before valid conclusions can be drawn. Furthermore, it might be advisable to introduce more objective measures since the students themselves might not have been able to fully and objectively judge on their knowledge gain.

In general, simulation games are a tool that should be increasingly used in higher education programs in eGovernment, as being disclosed by the evaluation, in order to introduce future public servants to the interdisciplinary environment, they will be employed in. It is crucial for practitioners to understand the importance of the specific context in which they are working to be able to bridge the existing gaps and, in the end, to create a better eGovernment reality.

There is a call for more research on innovative teaching methods in general and on higher education teaching as well as its effects as well as implications in the field of public administrations are needed.

\section{References}

[1] Accenture. Digitales Servicekonto für Bürger und Unternehmen. 2015.

[2] Adobor, H. and Daneshfar, A. Management simulations: determining their effectiveness. Journal of Management Development 25, 2 (2006), 151-168.

[3] Afonso, A., Schuknecht, L., and Tanzi, V. Public sector efficiency: evidence for new EU member states and emerging markets. Applied Economics 42, 17 (2010), 2147-2164.

[4] Aisopos, F., Kardara, M., Senger, P., et al. E-government and policy simulation in intelligent virtual environments. WEBIST 2012 - Proceedings of the 8th International Conference on Web Information Systems and Technologies, (2012), 129-135.

[5] Banerjee, P.K., Ma, L.C.K., and Shroff, R.H. Egovernance competence : a framework. Electronic Government, an International Journal 11, 3 (2015), 171184.

[6] Carter, L. and Bélanger, F. The utilization of egovernment services: citizen trust, innovation and acceptance factors. Information Systems Journal 15, (2005), 5-25.

[7] Cherns, A. The Principles of Sociotechnical Design. Human Relations 29, 8 (1976), 783-792.

[8] Distel, B. Die Einführung der elektronischen Akte in Deutschland. Digitale Transformation: Methoden, Kompetenzen und Technologien für die Verwaltung, Köllen Druck+Verlag GmbH (2016), 113-124.

[9] Ebrahim, Z. and Irani, Z. E- government adoption: architecture and barriers. Business Process Management Journal 11, 5 (2005), 589-611.

[10] European Commission. eGovernment. 2006. http://bit.ly/1UyXy1U.

[11] European Commission. A Digital Single Market Strategy for Europe. 2015.

[12] European Commission. Digital Single Market - Digital Economy \& Society. Digital Skills \& Jobs, 2016.

https://ec.europa.eu/digital-single-market/en/skills-jobs. [13] European Commission. eGovernment Benchmark 2016 A turning point for eGovernment development in Europe? Luxembourg, 2016.

[14] European Commission. eGovernment Benchmark 2017 Taking stock of user-centric design and delivery of digital 
public services in Europe. Luxembourg, 2017.

[15] European Commission. e-Identification. Policies, Information and Services, 2017. https://ec.europa.eu/digitalsingle-market/en/e-identification.

[16] Federal German Government. Gesetz zur Förderung der elektronischen Verwaltung (E-Government-Gesetz -

EGovG). 2013, 2749-2760.

[17] Federal Ministry of the Interior. IT Planning Council. 2018. https://www.it-

planungsrat.de/EN/home/home_node.html.

[18] Fletcher, J.D. and Tobias, S. Using computer games and simulations for instruction: A research review. Society for

Applied Learning Technology Meeting New Learning

Technologies, February (2006), 1-34.

[19] German Federal Government. German Digital Agenda

2014-2017. German Digital Agenda, 2017, 124.

[20] Gest, J., Reny, T., and Mayer, J. Roots of the Radical Right: Nostalgic Deprivation in the United States and Britain. Comparative Political Studies, (2017).

[21] Gil-García, J.R. and Pardo, T.A. E-government success factors: Mapping practical tools to theoretical foundations. Government Information Quarterly 22, 2 (2005), 187-216. [22] Greiling, D. Performance measurement: a remedy for increasing the efficiency of public services? International Journal of Productivity and Performance Management 55, 6 (2006), 448-465.

[23] Heeks, R. Most e-Government-for-Development Projects Fail How Can Risks be Reduced? 2003.

[24] Hunnius, S., Paulowitsch, B., and Schuppan, T. Does EGovernment education meet competency requirements? An analysis of the German university system from international perspective. Proceedings of the 48th Hawaii International Conference on System Sciences (HICSS-48), IEEE (2015), 2116-2123.

[25] Hunnius, S. and Schuppan, T. Competency requirements for transformational e-government. Proceedings of the 46th

Hawaii International Conference on System Sciences

(HICSS-46), IEEE (2013), 1664-1673.

[26] Janowski, T., Cellary, W., and Davies, J. Introduction to Electronic Government Education, Training and

Professionalization. Proceedings of the 46th Hawaii International Conference on System Sciences (HICSS-46), IEEE (2013), 1662-1663.

[27] Janowski, T., Estevez, E., and Ojo, A. Conceptualizing Electronic Governance Education. Proceedings of the 45th

Hawaii International Conference on System Sciences (HICSS-45), IEEE (2012), 2269-2278.

[28] Kaiser, S. Qualification Requirements in e-Government: The Need for Information Systems in Public Administration Education. Electronic Government: Proceedings of the 3 rd International Conference, EGOV 2004. LNCS 3183., Springer (2004), 464-467.

[29] Kalb, A., Geys, B., and Heinemann, F. Value for money? German local government efficiency in a comparative perspective. Applied Economics 44, 2 (2012), 201-218.

[30] Kim, G., Shin, B., Kim, K.K., and Lee, H.G. IT

Capabilities, Process-Oriented Dynamic Capabilities, and
Firm Financial Performance. Journal of Association for Information Systems 12, 7 (2011), 487-517.

[31] Klievink, B. and Janssen, M. Simulation games for collaborative development in e-Government. Proceedings of the 43rd Hawaii International Conference on System Sciences (HICSS-43), IEEE (2010), 1-9.

[32] Lean, J., Moizer, J., Towler, M., and Abbey, C. Simulations and games: Use and barriers in higher education. Active Learning in Higher Education 7, 3 (2006), 227-242.

[33] Leitner, C. eGovernment: People and skills in Europe's administrations. Proceedings of the 39th Hawaii International Conference on System Sciences, IEEE (2006), $1-9$.

[34] Mayer, I. and and Veeneman, W. Games in a world of infrastructures simulation-games for research, learning and intervention. Delft, 2002.

[35] Mayer, I., Bekebrede, G., Warmelink, H., and Zhou, Q. A Brief Methodology for Researching and Evaluating Serious Games and Game-Based Learning. In T.M. Connolly, T. Hainey, E. Boyle, G. Baxter and P. MorenoGer, eds., Psychology, Pedagogy, and Assessment in Serious Games. IG, 2013, 357-393.

[36] McIntosh, D. The uses and limits of the model United Nations in international relations classroom. International Studies Perspectives 2, (2001), 280-289.

[37] North Rhine-Westfalia. Municipal code for the state of North Rhine-Westphalia (GO NRW). Municipal code for the state of North Rhine-Westphalia (GO NRW), 2018.

http://www.lexsoft.de/cgi-

bin/lexsoft/justizportal_nrw.cgi?xid=146702,76.

[38] OECD. Core Skills for Public Sector Innovation: a Beta Model. 2017.

[39] Ogonek, N. and Becker, J. Can we Learn from Down Under How to Rise Up in E-Government? A Comparative Analysis of the Public Sector Competences in the German and Australian Higher Education Systems. Proceedings of the 51st Hawaii International Conference on System Sciences (HICCS-51), (2018), in press.

[40] Ogonek, N., Gorbacheva, E., Räckers, M., et al. Towards Efficient EGovernment: Identifying Important Competencies for EGovernment in European Public Administrations. Electronic Government and Electronic Participation. Proceedings of IFIP EGOV 2016 and ePart 2016, (2016), 155-162.

[41] Salas, E., Wildman, J., and Piccolo, R. Using Simulation-Based Training to Enhance Management Education. The Academy of Management Learning and Education (AMLE) 8, 4 (2009), 559-573.

[42] Schank, R.C. Lessons in Learning, e-Learning and Training. Pfeiffer, San Francisco, 2005.

[43] Tijdens, K. and Steijn, B. The determinants of ICT competencies among employees. New Technology, Work and Employment 20, 1 (2005), 60-73.

[44] Westera, W., Nadolski, R.J., Hummel, H.G.K., and Wopereis, I.G.J.H. Serious games for higher education: A framework for reducing design complexity. Journal of Computer Assisted Learning 24, 5 (2008), 420-432. 